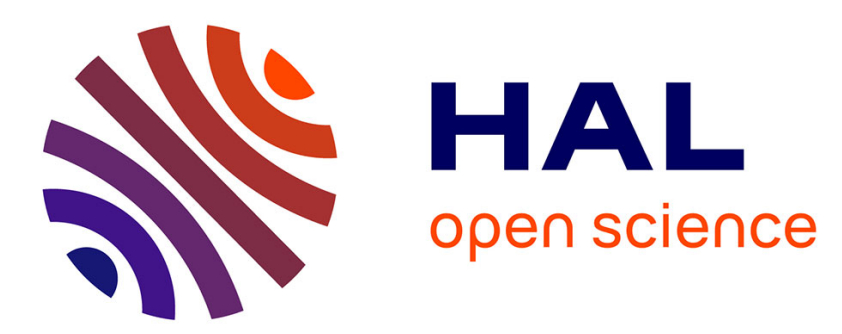

\title{
Human Infection with a Novel Avian-Origin Influenza A (H7N9) Virus.
}

Rongbao Gao, Bin Cao, Yunwen Hu, Zijian Feng, Dayan Wang, Wanfu Hu, Jian Chen, Zhijun Jie, Haibo Qiu, Ke Xu, et al.

\section{- To cite this version:}

Rongbao Gao, Bin Cao, Yunwen Hu, Zijian Feng, Dayan Wang, et al.. Human Infection with a Novel Avian-Origin Influenza A (H7N9) Virus.. New England Journal of Medicine, 2013, 368 (20), pp.1888-1897. 10.1056/NEJMoa1304459 . pasteur-00823211

\section{HAL Id: pasteur-00823211 https://hal-riip.archives-ouvertes.fr/pasteur-00823211}

Submitted on 16 May 2013

HAL is a multi-disciplinary open access archive for the deposit and dissemination of scientific research documents, whether they are published or not. The documents may come from teaching and research institutions in France or abroad, or from public or private research centers.
L'archive ouverte pluridisciplinaire HAL, est destinée au dépôt et à la diffusion de documents scientifiques de niveau recherche, publiés ou non, émanant des établissements d'enseignement et de recherche français ou étrangers, des laboratoires publics ou privés. 
ORIGINAL ARTICLE

\section{Human Infection with a Novel Avian-Origin Influenza A (H7N9) Virus}

\begin{abstract}
Rongbao Gao, M.D., Bin Cao, M.D., Yunwen Hu, M.D., Zijian Feng, M.D., M.P.H., Dayan Wang, M.D., Wanfu Hu, M.D., Jian Chen, M.D., Zhijun Jie, M.D., Haibo Qiu, M.D., Ph.D., Ke Xu, M.D., Xuewei Xu, M.D., Hongzhou Lu, M.D., Ph.D., Wenfei Zhu, M.D., Zhancheng Gao, M.D., Nijuan Xiang, M.D., Yinzhong Shen, M.D., Zebao He, M.D., Yong Gu, M.D., Zhiyong Zhang, M.D., Yi Yang, M.D., Ph.D., Xiang Zhao, M.D., Lei Zhou, M.D., Xiaodan Li, M.D., Shumei Zou, M.D., Ye Zhang, M.D., Xiyan Li, M.D., Lei Yang, M.D., Junfeng Guo, M.D., Jie Dong, M.D., Qun Li, M.D., Libo Dong, M.D., Yun Zhu, M.D., Tian Bai, M.D., Shiwen Wang, M.D., Pei Hao, M.D., Weizhong Yang, M.D., Yanping Zhang, M.D., Jun Han, M.D., Hongjie Yu, M.D., Dexin Li, M.D., George F. Gao, Ph.D., Guizhen Wu, M.D., Yu Wang, M.D., Zhenghong Yuan, Ph.D., and Yuelong Shu, Ph.D.
\end{abstract}

ABSTRACT

\section{BACKGROUND}

Infection of poultry with influenza A subtype $\mathrm{H} 7$ viruses occurs worldwide, but the introduction of this subtype to humans in Asia has not been observed previously. In March 2013, three urban residents of Shanghai or Anhui, China, presented with rapidly progressing lower respiratory tract infections and were found to be infected with a novel reassortant avian-origin influenza A (H7N9) virus.

\section{METHODS}

We obtained and analyzed clinical, epidemiologic, and virologic data from these patients. Respiratory specimens were tested for influenza and other respiratory viruses by means of real-time reverse-transcriptase-polymerase-chain-reaction assays, viral culturing, and sequence analyses.

\section{RESULTS}

A novel reassortant avian-origin influenza A (H7N9) virus was isolated from respiratory specimens obtained from all three patients and was identified as H7N9. Sequencing analyses revealed that all the genes from these three viruses were of avian origin, with six internal genes from avian influenza A (H9N2) viruses. Substitution Q226L (H3 numbering) at the 210-loop in the hemagglutinin (HA) gene was found in the A/Anhui/1/2013 and A/Shanghai/2/2013 virus but not in the A/Shanghai/1/2013 virus. A T160A mutation was identified at the 150-loop in the HA gene of all three viruses. A deletion of five amino acids in the neuraminidase (NA) stalk region was found in all three viruses. All three patients presented with fever, cough, and dyspnea. Two of the patients had a history of recent exposure to poultry. Chest radiography revealed diffuse opacities and consolidation. Complications included acute respiratory distress syndrome and multiorgan failure. All three patients died.

\section{CONCLUSIONS}

Novel reassortant H7N9 viruses were associated with severe and fatal respiratory disease in three patients. (Funded by the National Basic Research Program of China and others.)
The authors' affiliations are listed in the Appendix. Address reprint requests to Dr. Shu at the National Institute for Viral Disease Control and Prevention, Chinese Center for Disease Control and Prevention, Key Laboratory for Medical Virology, National Health and Family Planning Commission, 155 Changbai Rd., Beijing, 102206, China, or at yshu@cnic.org.cn; or to Dr. Yuan at the Key Lab of Medical Molecular Virology, School of Basic Medical Sciences, Shanghai Medical College of Fudan University, Shanghai City 200032, or at zhyuan@shmu.edu.cn.

*Drs. R. Gao, Cao, Y. Hu, Feng, D. Wang, W. Hu, Chen, Jie, and Qiu contributed equally to this study.

This article was published on April 11, 2013, at NEJM.org.

N EnglJ Med 2013. DOI: 10.1056/NEJMoal304459

Copyright (๑) 2013 Massachusetts Medical Society. 
PORADIC HUMAN INFECTIONS WITH avian influenza A viruses, which usually occur after recent exposure to poultry, have caused a wide spectrum of illness, ranging from conjunctivitis and upper respiratory tract disease to pneumonia and multiorgan failure. Low pathogenic avian influenza A (H7N2, H7N3, H9N2, or H10N7) ${ }^{1-4}$ virus infections have caused lower respiratory tract illness that is mild (conjunctivitis or uncomplicated influenza-like illness) to moderate in severity. Most human infections with highly pathogenic avian influenza (HPAI) A (H7) viruses have resulted in conjunctivitis (H7N3) or uncomplicated influenza illness, but one case of fatal acute respiratory distress syndrome (ARDS) was reported in a patient with $\mathrm{H} 7 \mathrm{~N} 7$ virus infection during an outbreak in the Netherlands. ${ }^{1,5}$ In contrast, the cumulative case fatality rate since 2003 for reported cases of HPAI $\mathrm{H} 5 \mathrm{~N} 1$ virus infection is approximately $60 \% .^{6-8}$

The transmission of $\mathrm{H} 7$ viruses to mammals has been reported only rarely ${ }^{9}$ in Asia. Human infections with N9 subtype viruses had not been documented anywhere in the world. In February and March 2013, three patients were hospitalized with severe lower respiratory tract disease of unknown cause. We report the identification of a novel avian-origin reassortant influenza A (H7N9) virus associated with these infections.

\section{METHODS}

SURVEILLANCE, REPORTING, AND DATA COLLECTION Throat-swab specimens obtained from three adult Chinese patients (two from Shanghai City and one from Anhui Province) who were hospitalized with severe bilateral pneumonia, leukopenia, and lymphocytopenia were sent to Shanghai Public Health Clinical Center, the Shanghai Centers for Disease Control and Prevention (CDC), and the Anhui CDC, respectively. After preliminary detection of respiratory pathogens, the samples were sent to the Chinese National Influenza Center (CNIC) on March 25, 2013.

A standardized surveillance reporting form was used to collect epidemiologic and clinical data, including demographic characteristics; underlying medical conditions; history of seasonal influenza vaccination; recent exposures to swine, poultry, or other animals; recent visits to a live animal market; clinical signs and symptoms; chest radiographic findings; laboratory testing results, including diagnostic testing for influenza and other respiratory viruses; antiviral treatment; clinical complications; and outcomes. A confirmed case of human infection with avian-origin influenza A (H7N9) virus was defined as evidence of pneumonia with H7N9 viral RNA or isolation of $\mathrm{H} 7 \mathrm{~N} 9$ virus from respiratory specimens at the CNIC.

\section{ISOLATION OF THE VIRUS}

Throat-swab specimens obtained from all three patients were maintained in a viral-transport medium. The specimens were propagated in the allantoic sac and amniotic cavity of 9-to-11-day-old specific pathogen-free embryonated chicken eggs for 48 to 72 hours at $35^{\circ} \mathrm{C}$.

\section{RNA EXTRACTION AND REAL-TIME RT-PCR}

RNA was extracted from throat-swab samples with the use of the QIAamp Viral RNA Mini Kit (Qiagen), according to the manufacturer's instructions. Specific real-time reverse-transcriptase-polymerase-chain-reaction (RT-PCR) assays for seasonal influenza viruses ( $\mathrm{H} 1, \mathrm{H} 3$, or $\mathrm{B})$, H5N1, severe acute respiratory syndrome coronavirus (SARS-CoV), and novel coronavirus were used. Real-time RT-PCR assays with self-designed specific primer and probe sets for detecting $\mathrm{H} 1$ to H16 and N1 to N9 subtypes were then performed to verify the viral subtypes.

\section{GENOME SEQUENCING AND PHYLOGENETIC ANALYSIS}

A total of 198 primer sets were used to amplify the full genome for sequencing, with the use of Qiagen OneStep RT-PCR Kit. PCR products were purified from agarose gel with the use of the QIAquick Gel Extraction Kit (Qiagen). We performed the sequencing using an ABI 3730xl automatic DNA analyzer (Life Technologies) and the ABI BigDye Terminator v3.1 cycle sequencing kit (Life Technologies), according to the manufacturer's recommendations. Full genome sequences of the viruses from these patients were deposited in the Global Initiative on Sharing Avian Influenza Data (GISAID) database on March 29, 2013 (accession numbers are provided in Table S1 in the Supplementary Appendix, available with the full text of this article at NEJM.org).

We performed multiple sequence alignments 


\begin{tabular}{|c|c|c|c|}
\hline Characteristic & Patient 1 & Patient 2 & Patient 3 \\
\hline Age (yr) & 87 & 27 & 35 \\
\hline Sex & Male & Male & Female \\
\hline Occupation & Retired & Butcher & Housewife \\
\hline Underlying conditions & COPD, hypertension & Hepatitis B & $\begin{array}{l}\text { Depression, hepatitis B, } \\
\text { obesity }\end{array}$ \\
\hline Area of origin & Shanghai & Shanghai & Anhui \\
\hline Exposure to chicken market in past 7 days & No & Yes & Yes \\
\hline Date of illness onset & February 18, 2013 & February 27, 2013 & March 13, 2013 \\
\hline Date of admission & February 25, 2013 & March 4, 2013 & March 19, 2013 \\
\hline Admission to ICU & None & March 6, 2013 & March 20, 2013 \\
\hline Date of specimen collection & February 26, 2013 & March 5, 2013 & March 20, 2013 \\
\hline Date of laboratory confirmation of virus & March 30, 2013 & March 30, 2013 & March 30, 2013 \\
\hline Viral isolation & A/Shanghai/1/2013 (H7N9) & A/Shanghai/2/2013 (H7N9) & A/Anhui/1/2013 (H7N9) \\
\hline \multicolumn{4}{|l|}{ Complications } \\
\hline Septic shock & No & No & Yes \\
\hline ARDS & Yes & Yes & Yes \\
\hline Acute renal damage & No & No & Yes \\
\hline Encephalopathy & Yes & No & Yes \\
\hline Rhabdomyolysis & No & Yes & Yes \\
\hline Secondary infections & No & Yest' & Yes广 \\
\hline Oxygen therapy & Mask & Mechanical ventilation & Mechanical ventilation \\
\hline Extracorporeal membrane oxygenation & No & No & Yes \\
\hline Continuous renal-replacement therapy & No & No & Yes \\
\hline Antibiotic therapy & $\begin{array}{l}\text { Imipenem, moxifloxacin, } \\
\text { and vancomycin }\end{array}$ & $\begin{array}{l}\text { Cefoperazone-sulbactam, } \\
\text { levofloxacin, and linezolid }\end{array}$ & Imipenem and vancomycin \\
\hline Antiviral agent $\int$ & $\begin{array}{c}\text { Oseltamivir } \\
\text { (started on day 7) }\end{array}$ & $\begin{array}{l}\text { Oseltamivir and amantadine } \\
\text { (started on day } 7 \text { ) }\end{array}$ & $\begin{array}{c}\text { Oseltamivir } \\
\text { (started on day 8) }\end{array}$ \\
\hline Glucocorticoid therapy & Yes & Yes & Yes \\
\hline Intravenous immune globulin therapy & Yes & Yes & Yes \\
\hline Length of stay in hospital & 6 days & 6 days & 19 days \\
\hline Date of death & March 4, 2013 & March 10, 2013 & April 9, 2013 \\
\hline
\end{tabular}

* ARDS denotes acute respiratory distress syndrome, and COPD chronic obstructive pulmonary disease.

$\uparrow$ Patients 2 and 3 were infected with carbapenem-resistant Acinetobacter baumannii.

$t$ This patient refused intubation and mechanical ventilation.

$\int$ Oseltamivir was administered in Patient 1 on February 25, 2013; the viral sample was obtained after two doses of oseltamivir were administered. Oseltamivir was administered in Patient 2 on March 6, 2013, and in Patient 3 on March 21, 2013.

with the ClustalW program using MEGA software, version 5.05. Phylogenetic trees were constructed by means of the neighbor-joining method with the use of MEGA software, version 5.05, to estimate the viral gene relationship with selected influenza A virus strains obtained from GenBank.

\section{RESULTS}

\section{PATIENTS}

Patient 1 was an 87-year-old man with chronic obstructive pulmonary disease (COPD) and hypertension who reported a cough and sputum production at the onset of illness. High fever and dyspnea de- 
veloped 1 week after the onset of illness. He had no known history of exposure to live birds during the 2 weeks before the onset of symptoms.

Patient 2 was a 27-year-old man with a history of hepatitis $\mathrm{B}$ virus infection with positive hepatitis B surface antigen who presented to the hospital with high fever and cough. This patient was a butcher who worked at a market where there were transactions involving live birds. He sold pork but had not butchered bird meat before the onset of illness. Both Patient 1 and Patient 2 lived in Min-hang District, Shanghai, and were admitted to the Fifth People's Hospital.

Patient 3 was a 35-year-old woman who lived in Anhui Province. She had a history of depression, hepatitis B virus infection, and obesity. Patient 3 also had high fever and cough at the onset of the illness. She had visited a chicken market 1 week before the onset of symptoms. The demographic and epidemiologic characteristics of the three patients are summarized in Table 1.

\section{DETERMINATION OF CAUSATIVE PATHOGENS}

We confirmed, by means of real-time RT-PCR, viral isolation, and full genome sequencing, that all three patients were infected with a novel avianorigin influenza A (H7N9) virus. Original clinical samples obtained from all three patients were confirmed, by means of real-time RT-PCR, to be positive for $\mathrm{H} 7 \mathrm{~N} 9$ and negative for seasonal influenza viruses (H1, H3 or B), H5N1, SARS-CoV, and HCoV-Erasmus Medical Center (EMC). Influenza viruses A/Shanghai/1/2013 (H7N9), A/ Shanghai/2/2013 (H7N9), and A/Anhui/1/2013 (H7N9) were isolated from Patients 1, 2, and 3, respectively. Complete sequences of the three H7N9 influenza viruses showed that they were 97.7 to $100 \%$ identical in all eight gene segments (see Table S1 in the Supplementary Appendix). Phylogenetic analysis of all genes of the isolates showed that each gene was of avian origin (Fig. 1, and Fig. S1 in the Supplementary Appendix). The gene encoding hemagglutinin (HA) shared the highest identity with A/duck/Zhejiang/12/2011 (H7N3, subtype ZJ12). The gene encoding neuraminidase (NA) protein was most closely related to A/wild bird/Korea/A14/2011 (H7N9, subtype KO14); however, the HA gene from the H7N9 viruses in our three patients was highly divergent from that in the KO14 virus. All six internal genes shared the highest similarity with $\mathrm{A} / \mathrm{brambling} /$
Figure 1 (facing page). Phylogenetic Trees of Genes of H7N9 Influenza A Viruses.

Shown are phylogenetic trees of full-length hemagglutinin $(\mathrm{HA}$; Panel A) and neuraminidase (NA; Panel B) genes of $H 7 N 9$ influenza $A$ viruses. The trees were generated by means of the distance-based neighbor-joining method with the use of MEGA software, version 5.05. The reliability of the trees was assessed by means of bootstrap analysis with 1000 replications. Horizontal distances are proportional to the genetic distance. The novel reassortant H7N9 viruses are shown in red. The viruses in green presented the highest similarity with the novel H7N9 viruses. Other $\mathrm{H} 7 \mathrm{~N} 9$ and human $\mathrm{H} 7$ subtype are shown in blue and pink, respectively. Phylogenetic trees of the other six genes are included in the Supplementary Appendix.

Beijing/16/2012-like viruses (H9N2) (Fig. 1). Phylogenetic results indicated that it was a triple reassortant H7N9 virus (Fig. 2).

In all three viruses, the HA cleavage site possesses only a single amino acid $\mathrm{R}$ (arginine), indicating low pathogenic effects in poultry. A T160A mutation was identified at the 150-loop (H3 numbering) in the HA gene of all three viruses. Substitution Q226L at the 210-loop in the HA gene was found in both the A/Anhui/1/2013 and A/Shanghai/2/2013 viruses but not in the A/ Shanghai/1/2013 virus (Table 2). Five amino acids were deleted in the stalk region of NA residue 69 to 73. The M2 protein contained the S31N substitution, indicating resistance to amantadine. Other mutations - 89V and E627K in PB2 and 42S in NS1 - were also identified (Table 2). The amino acids in A/Shanghai/1/2013, which differed from those in A/Anhui/1/2013 and A/Shanghai/2/2013, are shown in Table S2 in the Supplementary Appendix. To date, five additional H7N9 viruses have been isolated from five patients. Sequencing analysis indicates that all five viruses are highly similar to both A/ Shanghai/2/2013 and A/Anhui/1/2013. Some variability is observed, such as Q226L in HA and $\mathrm{R} 292 \mathrm{~K}$ in NA.

On the basis of these data, diagnostic tests for the novel reassortant H7N9 viruses have been developed. The specific sequences are available on the website of the World Health Organization (www.who.int/influenza/gisrs_ laboratory/a_h7n9/en/).

\section{CLINICAL FEATURES AND OUTCOMES OF THE PATIENTS}

The clinical characteristics of the patients are shown in Table S3 in the Supplementary Appen- 


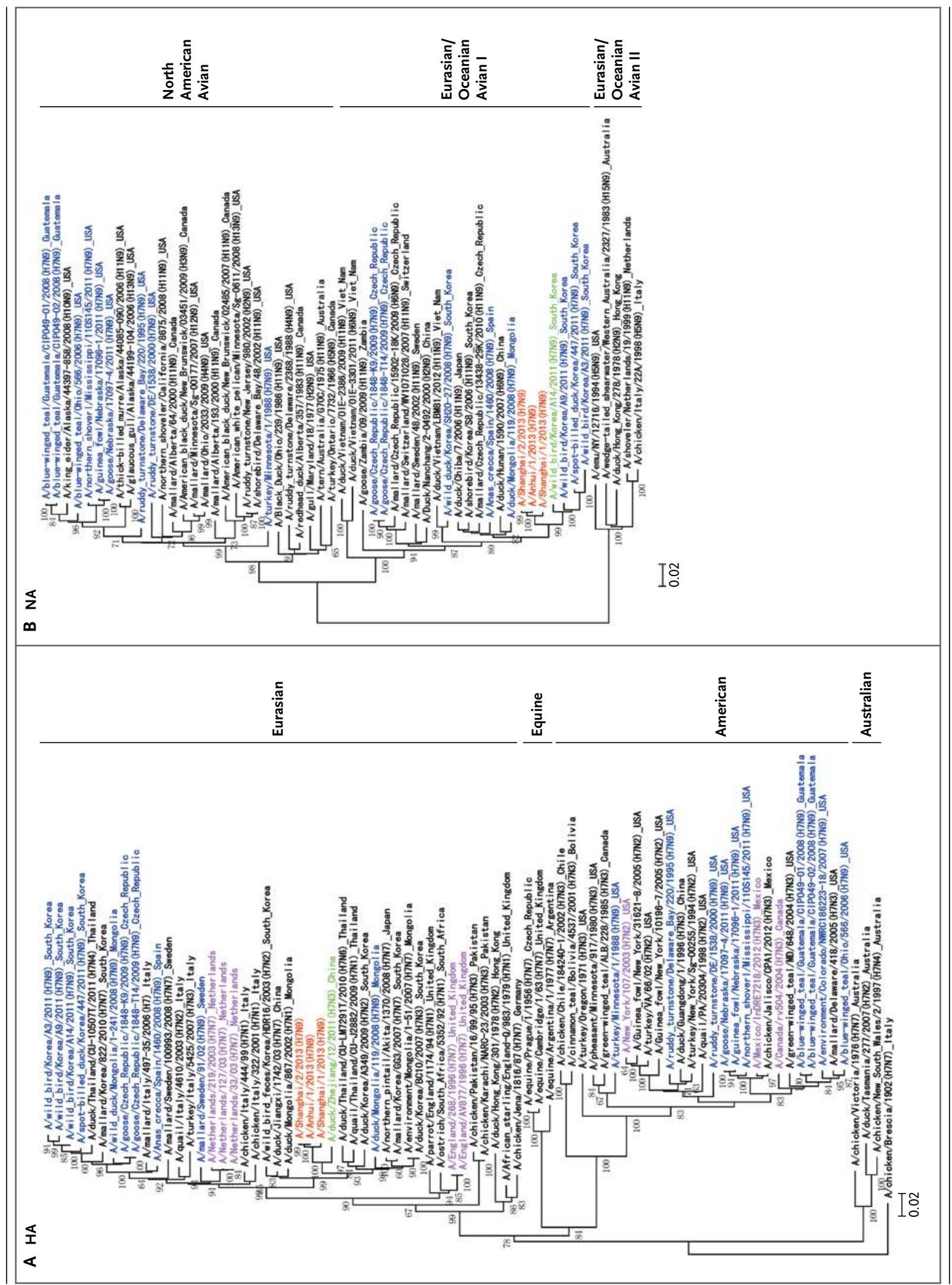






dix. Fever and cough were the most common symptoms. The white-cell count was normal or slightly decreased. Elevated levels of aspartate aminotransferase, creatine kinase, and lactate dehydrogenase were observed in all the patients. Bilateral ground-glass opacities and consolidation were detected on chest radiography (Fig. 3). Several complications of the illness were ob- 


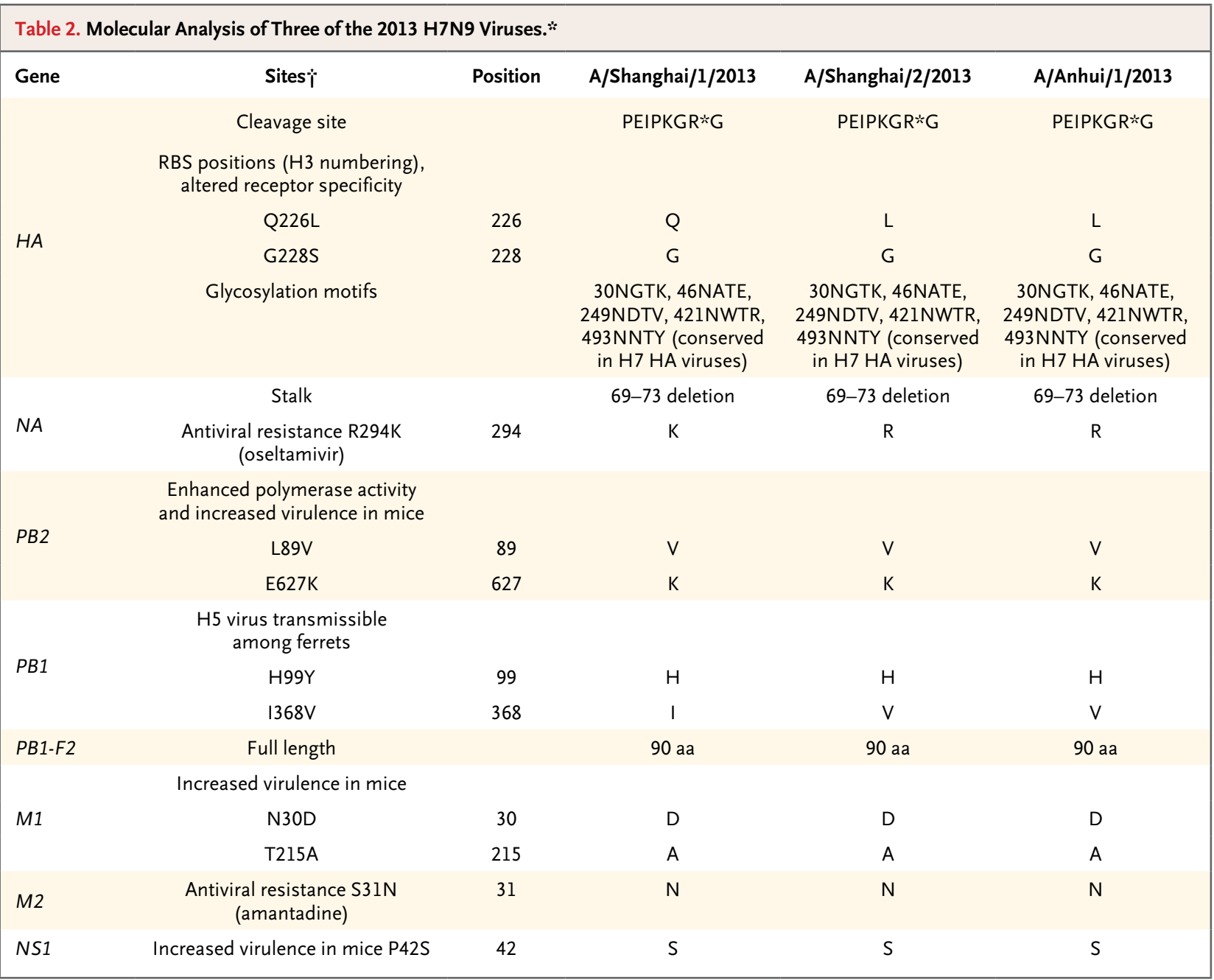

* Single letters refer to the amino acid (aa) found in the noted gene at a specific site.

$\dagger$ Sites are numbered from $M$, the start codon.

served. All the patients had ARDS. Patient 3 had septic shock and acute renal damage. Carbapenem-resistant Acinetobacter baumannii was cultured from lower respiratory tract specimens obtained from two of the patients after the initiation of mechanical ventilation. Combination antibiotic therapy, glucocorticoids, and intravenous immunoglobulin were administered in all three patients. Antiviral therapy was initiated 6 to 7 days after the onset of illness (Table 1).

Patient 1 declined admission to the intensive care unit (ICU) and intubation. He died from refractory hypoxemia 13 days after the onset of illness. Patient 2 was admitted to the ICU and intubated 48 hours after admission owing to progressive dyspnea. He died from refractory hypoxemia after 4 days in the ICU. ARDS and septic shock developed in Patient 3 on day 6 af- ter the onset of illness. She was admitted to the ICU, and extracorporeal membrane oxygenation was initiated. She died on April 9.

\section{DISCUSSION}

We have identified a novel reassortant influenza A (H7N9) virus that is associated with severe human infection. Currently, only 25 H7N9 viruses are available in GenBank. The H7N9 viruses we identified in the three patients were of avian origin, but only the NA gene was closely related to that from another H7N9 virus (KO14). The HA gene was similar to that of an H7N3 virus (ZJ12) from a nearby region (Zhejiang Province) in China. All the internal gene segments were closely related to those from avian H9N2 viruses, particularly a virus isolated from a brambling in Bei- 


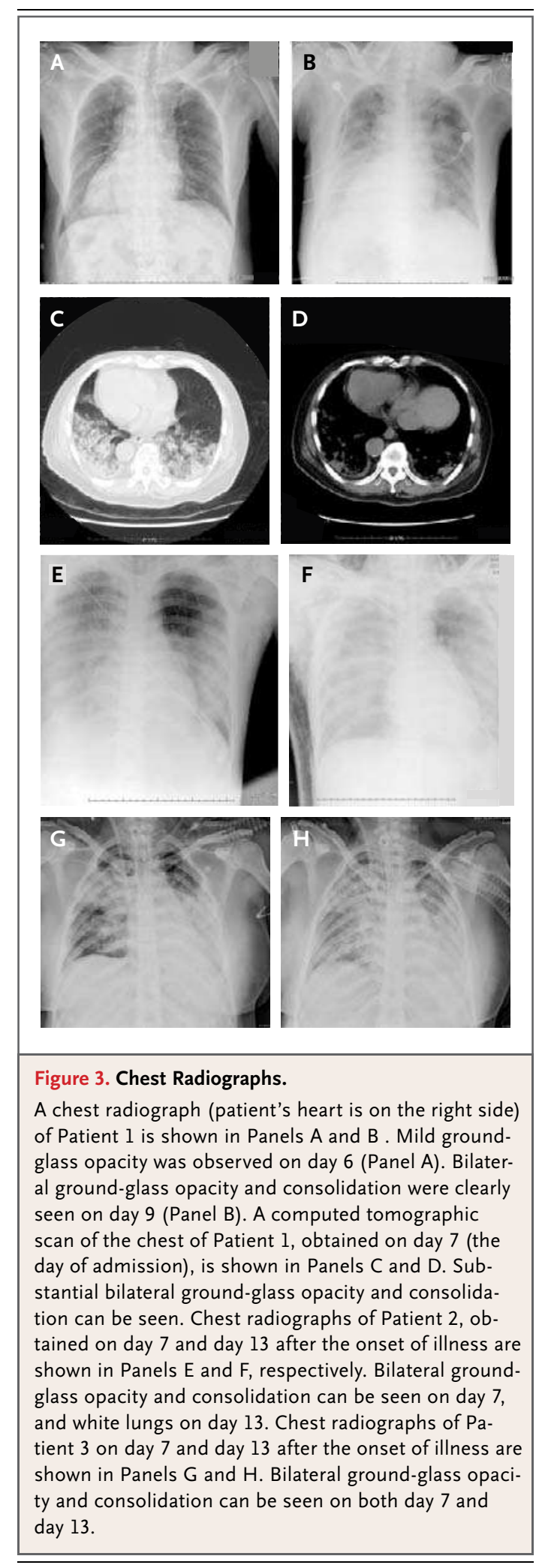

jing (BJ16) (Fig. 1, and Fig. S1 in the Supplementary Appendix). Thus, the human H7N9 viruses are the product of reassortment of viruses that are of avian-origin only. In addition, the phylogenetic trees showed that A/Shanghai/1/2013 is phylogenetically distinct from A/Anhui/1/2013 and A/Shanghai/2/2013 across all gene segments, which suggests that there have been at least two introductions into humans (Fig. 1, and Fig. S1 in the Supplementary Appendix). Currently, there are no data to suggest that this reassortment occurred in a mammalian host, and the similarity of the human viruses to avian viruses may be stronger support for direct avian transmission of this virus. However, influenza surveillance of birds, swine, and humans is limited in China and nearby countries, making it difficult to resolve this question.

Although human infections with avian-origin $\mathrm{H} 7$ avian influenza viruses have been observed before, 1,2,5,10,11 infection of humans with an N9 subtype influenza virus has not been reported previously. Human $\mathrm{H} 7$ influenza infections are generally mild, causing conjunctivitis or modest respiratory symptoms, although a fatal case was reported before this H7N9 outbreak. ${ }^{5}$ All three cases of H7N9 infection reported here were virulent, with the patients' conditions deteriorating rapidly with the development of severe pneumonia and ARDS, and ultimately resulted in death. All the patients had preexisting medical conditions, and two had a history of direct contact with poultry. Two patients presented with rhabdomyolysis, which has rarely been reported in patients infected with $\mathrm{H} 1 \mathrm{~N} 1$ or $\mathrm{H} 5 \mathrm{~N}^{12}{ }^{12}$ influenza viruses. Encephalopathy, which is normally more common in pediatric patients with influenza, ${ }^{13}$ was observed in two patients.

The affinity of the influenza virus to different sialyl-sugar structures is an important determinant of range and pathogenicity in the viral host. ${ }^{14,15}$ Human influenza viruses preferentially bind to $\alpha 2,6$ sialyl glycan, whereas most avian viruses bind to $\alpha 2,3$ sialyl glycan. ${ }^{16,17}$ Q226L in the HA protein, which was first reported in $\mathrm{H} 7$ field viruses, as well as $\mathrm{H} 5$ subtypes, was expected to bind strongly to $\alpha-2,6$ human-like receptors. A laboratory-produced Q226L mutation at the 210-loop of HA has been shown to change the receptor binding of avian origin to a human- 
type receptor binding and might increase the ability of the virus to be transmitted by air, as reported previously. ${ }^{18,19}$ Moreover, the lack of a glycosylation site on the 150-loop might decrease the affinity to $\alpha-2,3$ avian-like receptors. The effects of these mutations require further study.

A deletion of five amino acids in the viral NA stalk has been observed in the novel reassortant $\mathrm{H} 7 \mathrm{~N} 9$ viruses. A similar deletion in the $\mathrm{H} 5 \mathrm{~N} 1$ avian virus has been shown to be responsible for the change in viral tropism to the respiratory tract $^{20}$ or to enhance viral replication, ${ }^{21}$ and it has been suggested that this deletion may be associated with adaptation and transmission in domestic poultry. ${ }^{22,23}$ Since April 4, it has been reported that $\mathrm{H} 7 \mathrm{~N} 9$ viruses similar to those isolated from the three patients described here have been isolated from pigeons and chickens, indicating that the novel H7N9 viruses might currently be circulating in poultry. Moreover, the E627K substitution in the PB2 gene has been associated with increased virulence in mice and was reported to be associated with improved replication of avian influenza viruses in mammals. ${ }^{24,25} \mathrm{~A}$ combination of these substitutions may contribute to the human infection and severe disease. Other possible virulence molecular markers are shown in Table 2. The potential virulence mutations are described on the basis of previous studies in animals, but the pathogenesis in humans remains unknown.

The difference between the two Shanghai viruses and the similarity between the Shanghai/2 and Anhui/ 1 viruses argue against human-tohuman transmission in these cases, and no close contacts of the patients have tested positive for these viruses. However, limited human-tohuman transmission was observed in the $\mathrm{H} 7$ outbreak in the Netherlands in $2003^{10}$; therefore, the pandemic potential of these novel avian-origin viruses should not be underestimated.
Currently there is no vaccine available for these novel viruses, and it is not known whether the current candidate $\mathrm{H} 7$ vaccine viruses, of which three are North American viruses and the other three are avian viruses from 2000 in the Netherlands, may be effective. The influenza H7N9 A/Anhui/1/2013 strain has been proposed to be one of the candidate vaccine strains since it grows to a very high titer in eggs. Heightened protective measures should be taken when dealing with these viruses, and increased surveillance and analyses of these viruses are needed.

Severe avian influenza A (H7N9) infections, characterized by high fever and severe respiratory symptoms, may pose a serious human health risk. We are concerned by the sudden emergence of these infections and the potential threat to the human population. An understanding of the source and mode of transmission of these infections, further surveillance, and appropriate counter measures are urgently required.

The contents of this article are solely the responsibility of the authors and do not necessarily represent the views of the Centers for Disease Control and Prevention in China or other organizations.

Supported by a grant (2011CB504704) from the National Basic Research Program (973) of China, grants (81070005/H0104 and 81030032/H19) from the National Natural Science Foundation of China, grants from the China National Mega-projects for Infectious Diseases (2012ZX10004-211 to Dr. Yuan and 2013ZX10004101 to Dr. Dexin Li), and the Chinese National Influenza Center-Centers for Disease Control and Prevention (CDC) collaborative project 5U51IP000334-03 from the CDC ChinaU.S. Collaborative Program on Emerging and Re-emerging Infectious Diseases.

Disclosure forms provided by the authors are available with the full text of this article at NEJM.org.

We thank Prof. Chen Wang in Beijing Hospital, Ministry of Health, for his advice in clinical study, data analysis, and preparation of the manuscript; Dr. Yunde Hou (Chinese Center for Disease Control and Prevention) and Yumei Wen (Fudan University) for their suggestions and discussion; the staff at the National Health and Family Planning Commission for help with coordination; and personnel at the Chinese National Influenza Surveillance Network and National Sci-Tech Key Project of Infectious Disease Surveillance Laboratory Network, China.

The authors' affiliations are as follows: the National Institute for Viral Disease Control and Prevention, Chinese Center for Disease Control and Prevention (R.G., D.W., W.Z., X.Z., X.L., S.Z., Y.Z., X.L., L.Y., J.G., J.D., L.D., Y.Z., T.B., S.W., J.H., D.L., G.W., Y.S.), Beijing Chao-Yang Hospital, Beijing Institute of Respiratory Diseases, Capital Medical University (B.C.), Chinese Center for Disease Control and Prevention (Z.F., N.X., L.Z., Q.L., W.Y., Y.Z., H.Y., G.F.G., Y.W.), and Peking University People's Hospital (Z.G.), Beijing; Shanghai Public Health Clinical Center, Shanghai Medical College of Fudan University (Y.H., H.L., Y.S., Z.Z., Z.Y.), Shanghai Municipal Center for Disease Control and Prevention (J.C.), the Fifth People's Hospital of Shanghai, Fudan University (Z.J., Z.H., Y.G.), and Institute Pasteur of Shanghai, Chinese Academy of Sciences (P.H.), Shanghai; Anhui Provincial Center for Disease Control and Prevention, Hefei (W.H.); Zhongda Hospital, Southeast University (H.Q., Y.Y.), and Jiangsu Provincial Center for Disease Prevention and Control (K.X.), Nanjing; and Chuzhou Center for Disease Control and Prevention, Chuzhou (X.X.) - all in China. 
REFERENCES

1. Hirst M, Astell CR, Griffith $M$, et al. Novel avian influenza H7N3 strain outbreak, British Columbia. Emerg Infect Dis 2004;10:2192-5.

2. Nguyen-Van-Tam JS, Nair P, Acheson $\mathrm{P}$, et al. Outbreak of low pathogenicity H7N3 avian influenza in UK, including associated case of human conjunctivitis. Euro Surveill 2006;11:E060504.2.

3. Avian influenza $\mathrm{A} /(\mathrm{H} 7 \mathrm{~N} 2)$ outbreak in the United Kingdom. Euro Surveill 2007; 12:E070531.2.

4. Arzey GG, Kirkland PD, Arzey KE, et al. Influenza virus A (H10N7) in chickens and poultry abattoir workers, Australia. Emerg Infect Dis 2012;18:814-6.

5. Fouchier RA, Schneeberger PM, Rozendaal FW, et al. Avian influenza A virus (H7N7) associated with human conjunctivitis and a fatal case of acute respiratory distress syndrome. Proc Natl Acad Sci U S A 2004;101:1356-61.

6. Yuen KY, Chan PK, Peiris $M$, et al. Clinical features and rapid viral diagnosis of human disease associated with avian influenza A H5N1 virus. Lancet 1998; 351:467-71.

7. Nicholson KG, Wood JM, Zambon M. Influenza. Lancet 2003;362:1733-45.

8. Peiris JS, de Jong MD, Guan Y. Avian influenza virus (H5N1): a threat to human health. Clin Microbiol Rev 2007;20: 243-67.

9. Kwon TY, Lee SS, Kim CY, Shin JY, Sunwoo SY, Lyoo YS. Genetic characterization of H7N2 influenza virus isolated from pigs. Vet Microbiol 2011;153:393-7. 10. Koopmans M, Wilbrink B, Conyn M, et al. Transmission of H7N7 avian influenza A virus to human beings during a large outbreak in commercial poultry farms in the Netherlands. Lancet 2004; 363:587-93.

11. Tweed SA, Skowronski DM, David ST, et al. Human illness from avian influenza H7N3, British Columbia. Emerg Infect Dis 2004;10:2196-9.

12. D'Silva D, Hewagama S, Doherty R, Korman TM, Buttery J. Melting muscles: novel H1N1 influenza A associated rhabdomyolysis. Pediatr Infect Dis J 2009;28: 1138-9.

13. Ekstrand JJ. Neurologic complications of influenza. Semin Pediatr Neurol 2012;19:96-100.

14. Horimoto T, Kawaoka Y. Influenza: lessons from past pandemics, warnings from current incidents. Nat Rev Microbio 2005;3:591-600.

15. Suzuki Y. Sialobiology of influenza: molecular mechanism of host range variation of influenza viruses. Biol Pharm Bull 2005;28:399-408.

16. Ito T, Kawaoka Y. Host-range barrier of influenza A viruses. Vet Microbio 2000;74:71-5.

17. Skehel JJ, Wiley DC. Receptor binding and membrane fusion in virus entry: the influenza hemagglutinin. Annu Rev Biochem 2000;69:531-69.

18. Herfst S, Schrauwen EJ, Linster M, et al. Airborne transmission of influenza A/ H5N1 virus between ferrets. Science 2012;336:1534-41.

19. Imai $M$, Watanabe $T$, Hatta $M$, et al. Experimental adaptation of an influenza
H5 HA confers respiratory droplet transmission to a reassortant $\mathrm{H} 5 \mathrm{HA} / \mathrm{H} 1 \mathrm{~N} 1$ virus in ferrets. Nature 2012;486:420-8. 20. Sorrell EM, Song H, Pena L, Perez DR. A 27-amino-acid deletion in the neuraminidase stalk supports replication of an avian $\mathrm{H} 2 \mathrm{~N} 2$ influenza $A$ virus in the respiratory tract of chickens. J Virol 2010; 84:11831-40.

21. Baigent SJ, McCauley JW. Glycosylation of haemagglutinin and stalk-length of neuraminidase combine to regulate the growth of avian influenza viruses in tissue culture. Virus Res 2001;79:177-85.

22. Guan Y, Peiris JS, Lipatov AS, et al. Emergence of multiple genotypes of H5N1 avian influenza viruses in Hong Kong SAR. Proc Natl Acad Sci U S A 2002;99:8950-5.

23. Li J, Zu Dohna H, Cardona CJ, Miller J, Carpenter TE. Emergence and genetic variation of neuraminidase stalk deletions in avian influenza viruses. PLoS One 2011;6(2):e14722.

24. Hatta M, Gao P, Halfmann P, Kawaoka Y. Molecular basis for high virulence of Hong Kong H5N1 influenza A viruses. Science 2001;293:1840-2.

25. Labadie K, Dos Santos Afonso E, Rameix-Welti MA, van der Werf S, Naffakh $\mathrm{N}$. Host-range determinants on the PB2 protein of influenza A viruses control the interaction between the viral polymerase and nucleoprotein in human cells. Virology 2007;362:271-82.

Coppright (c) 2013 Massachusetts Medical Society. 